\title{
Calibration and field performance of triolein embedded acetate membranes for passive sampling persistent organic pollutants in water
}

\author{
Jianfeng Tang, Shan Chen, Yiping Xu, Wenjue Zhong, Mei Ma, Zijian Wang* \\ State Key Laboratory of Environmental Aquatic Chemistry, Research Center for Eco-Environmental Sciences, Chinese Academy of Sciences, Beijing 100085, PR China
}

\section{A R T I C L E I N F O}

\section{Article history:}

Received 2 October 2011

Received in revised form

9 January 2012

Accepted 15 January 2012

\section{Keywords:}

Calibration

Triolein embedded cellulose acetate

membranes TECAM

Performance reference compounds PRCs

Passive sampling

\begin{abstract}
A B S T R A C T
Triolein embedded cellulose acetate membrane (TECAM) passive samplers provide potentially powerful tool for monitoring time weighted average concentrations $\left(C_{\mathrm{TWA}}\right)$ of trace hydrophobic organic contaminants in water. To study the field performance of TECAM, exchange kinetics of chemicals between water and TECAM were studied at different temperature and water flow rates. Results showed that the uptake rate constant $\left(k_{\mathrm{u}}\right)$ in TECAM was less sensitive to temperature variation than the SPMD and Chemcatcher. The $k_{\mathrm{u}}$ in TECAM was sensitive to even a slight change of the flow rate, which required the field calibration using performance reference compounds (PRCs). To estimate $C_{\text {TWA }}$ by TECAM, both empirical model and WBL model were compared in laboratory conditions, and only small differences were observed between the predicted and measured $k_{\mathrm{u}}$. Field validation was conducted to test the sampler performance alongside spot sampling. A good agreement of water concentration was obtained by the two sampling techniques.
\end{abstract}

(c) 2012 Elsevier Ltd. All rights reserved.

\section{Introduction}

Passive sampling is based on the free flow of analyte molecules from the sampled medium to the collecting medium by effect of a difference in chemical potential of the analyte between the two mediums. The collecting medium usually consists of a diffusion limiting layer and a receiving phase. Based on this principle, passive samplers have been designed with various geometries and materials of construction to suit different applications (Esteve-Turrillas et al., 2008; Rubio and Ballesteros-Gomez, 2011). Remarkable progress has been made in recent years with regard to application of passive samplers. A range of new passive sampling devices and set-ups have been developed for monitoring organic pollutants in aquatic environments. Potential applications of this approach for monitoring nonpolar industrial pollutants in the aqueous environment have been recently reviewed (Esteve-Turrillas et al., 2008; Gorecki et al., 2008; Greenwood et al., 2009; Soderstrom et al., 2009).

Calibration of passive samplers may be achieved by measuring uptake rates $\left(k_{\mathrm{u}}\right)$ (the volume of water cleared of chemical per unit sampler mass or volume per time) or sampling rates $\left(R_{\mathrm{S}}\right)$ (the volume of water cleared per unit time) in the laboratory for the range of exposure conditions that are encountered in the field. However, the determination of the parameters that are needed to

\footnotetext{
* Corresponding author.

E-mail address: wangzj@rcees.ac.cn (Z. Wang).
}

calculate in situ $R_{\mathrm{S}}$ or $k_{\mathrm{u}}$ may not be always be possible (O'Brien et al., 2011).

Accurate uptake rates or sampling rates are required to determine the time weighted average concentration $\left(C_{\mathrm{TWA}}\right)$ of target analytes. However, it is well known that $k_{\mathrm{u}}$ or $R_{\mathrm{S}}$ is affected by a range of environmental variables including temperature (Huckins et al., 1999; Booij et al., 2003; Vrana et al., 2006b), water flow velocity and turbulence (Vrana and Schuurmann, 2002), and the biofouling on the surface of the sampler (Richardson et al., 2002; Booij et al., 2006). Changes in all these variables would affect uptake kinetics and sampling rates, and would affect the accuracy of estimated $C_{\text {twa }}$ under field conditions. To estimate ambient chemical concentration at field conditions by passive sampler is, therefore the challenge that requires the development of adequate calibration methods to fit into variable environmental conditions.

Methods involving use of passive samplers containing performance reference compounds (PRCs) has been introduced to resolve the problem for the in situ calibration and evaluation of site-specific variables (Huckins et al., 2002, 2006). PRCs are spiked into samplers prior to exposure, and under isotropic exchange, both PRCs dissipation and analyte uptake are theoretically equally affected by exposure environment, so the $k_{\mathrm{u}}$ or $R_{\mathrm{S}}$ can be estimated from the loss of PRCs. Estimation of $k_{\mathrm{u}}$ or $R_{\mathrm{S}}$ from the PRCs' dissipation parameters provides a mean to evaluate the influence of the exposure variables on the uptake kinetics and thus calculate the $k_{\mathrm{u}}$ of the analytes by passive samplers. The application of PRCs method 
has been applied to many passive samplers such as semipermeable membrane devices (SPMD) (Huckins et al., 2002), polyethylene passive sampler (Adams et al., 2007; Fernandez et al., 2009), silicone rubber (SR) passive samplers (Rusina et al., 2010), Chemcatcher (Vrana et al., 2006b) and polar organic chemical integrative sampler (POCIS) (Mazzella et al., 2010).

TECAM has been developed in our laboratory for in situ passive sampling of hydrophobic organic pollutants in water (Ke et al., 2007b) and soil (Tao et al., 2009). This passive sampler can quickly and efficiently accumulate hydrophobic organic compounds (Esteve-Turrillas et al., 2008), and it needs shorter time to achieve equilibrium than SPMD (Esteve-Turrillas et al., 2007). Therefore, the objective of this study was to investigate the impact of environmental variables on sampling performance of TECAM, and to evaluate the potential use of PRCs for in situ calibration of TECAM. As in the configuration of TECAM, triolein was closely encapsulated by the outer cellulose acetate membrane polymers, the spiking cannot be conducted directly by injecting into the membrane like SPMD. Therefore, an incubation PRC method for TECAM was developed in this study.

\section{Materials and methods}

\section{Materials}

Standards of selected four PAHs (anthracene, pyrene, chrysene, perylene) and three deuterated PAH standards used as PRCs, as well as hexamethylbenzene were purchased from Supelco Inc. (Bellefonte, PA). All organic solvents of HPLC grade were obtained from Fisher Scientific (Fair Lawn, NJ) and J. T. Baker (Phillipsburg, NJ) TECAM were constructed as described by Xu et al. (2005). All TECAM were constructed in the same configuration: $40-50 \mu \mathrm{m}$ thick, $12 \mathrm{~cm}$ wide, and $18 \mathrm{~cm}$ long embedded with $7.5 \mathrm{wt} \%$ of triolein. Unfortified TECAMs of original size were used directly for sampling experiments in field. Membranes were cut into small pieces $(4 \times 6 \mathrm{~cm})$ to use in all laboratory and field depletion experiments. Small pieces of PRC-based TECAM used in all experiments were fortified with chrysene- $d 12$, anthracene- $d 10$, and pyrene- $d 10$ as PRCs. For PRC spiking, every 10 pieces of TECAM were incubated in $1000 \mathrm{~mL}$ of water solution containing $100 \mathrm{ng} / \mathrm{L}$ of PRCs in flasks. The flasks were sealed and subjected to an ultrasonic bath for $1 \mathrm{~h}$, followed by equilibration overnight on a shaker. Immediately before use, the solution sticking to the membranes was removed by wiping the membranes with paper tissue. For laboratory verification, 4 pieces from each batch were analyzed to determine the spiking level. Field blank TECAM (i.e., those treated identically to sample TECAM during transport and deployment but not exposed to the sample) was also used for estimation of $C_{\mathrm{PRC}-0}$ in the field application.

\subsection{Laboratory exposure experiments}

\subsubsection{Effects of temperature}

Bach experiments were carried out with a negligible depletion sampling method as described previously (Ke et al., 2007a). One piece of membrane was exposed in $1 \mathrm{~L}$ of ultrapure water spiked with $1000 \mathrm{ng} / \mathrm{L}$ of target PAHs. The flask was shaken at the speed of $100 \mathrm{r} / \mathrm{min}$. Membranes were removed after each hour exposure and placed into a new flask filled with $1 \mathrm{~L}$ test solution. Kinetics experiments were conducted by adding one piece of TECAM to the test solution for $1,2,3,6$ and $12 \mathrm{~h}$ at four water temperature treatments $\left(5,15,25\right.$ and $\left.35^{\circ} \mathrm{C}\right)$. All experiments were carried out in triplicates.

\subsubsection{Flow-through exposure}

TECAM passive samplers fortified with PRCs were exposed to test chemicals at a nominal concentration of $50 \mathrm{ng} / \mathrm{L}$ in a flow-through exposure system. The configuration of the flow exposure system consisted of an $18 \mathrm{~L}$ glass tank with an overflow to waste. In each experiment, 18 TECAM passive samplers were exposed in one glass tank, exposure water was pumped to the tank using a peristaltic pump. Test chemicals were dissolved in acetone and the appropriate amounts of stock solution were delivered into the exposure tank using a small peristaltic pump. The acetone concentration in the exposure water was below $0.01 \%(\mathrm{~V} / \mathrm{V})$. This setup enabled the manipulation of flow rates in the exposure tank.

Prior to each exposure, the system was operated for a minimum of $48 \mathrm{~h}$ without samplers to allow equilibration with the test solution. Exposures were conducted at $22^{\circ} \mathrm{C}$. The exposures lasted 10 days, during which tripartite samplers were sampled at set time intervals $(0,0.5,1,2,4,7,10 \mathrm{~d})$ and analyzed to determine the concentrations of PRCs and accumulated test chemicals. Duplicate samples (500 mL each) of water were also taken at each time the samplers were removed, and the concentration of test analyte in the water was determined. Each water sample was extracted by liquid-liquid extraction method with $25 \mathrm{~mL}$ of dichloromethane (DCM) for three times. In addition, a minimum of three samplers were analyzed prior to exposure to determine the initial concentrations of PRCs and analytes in blank samplers.

\subsection{Field deployment of TECAM}

Two sites of greatly different hydrodynamic conditions were selected in Wenyu River in Beijing, China. The water temperature at the sites varied from, approximately, 17 to $22{ }^{\circ} \mathrm{C}$ during the exposure. TECAM were suspended in stainless steel mesh cages with solid tops that provided shade from the sun. After deployment, three fortified TECAM replicates were sampled at $1,2,4,8$, and 16 days separately. Unfortified TECAM of large size were removed 2 days after exposure, ensuring that uptake remained in the linear phase. All TECAM were retrieved and the exterior was rinsed directly using ambient water from the site. They were then placed in sealed glass jars, transported to the laboratory and stored at $4{ }^{\circ} \mathrm{C}$ awaiting analysis. Natural surface water samples $(2 \mathrm{~L})$ were collected in duplicate before and after the exposure course of unfortified TECAM. The samples were immediately filtered through $0.45 \mu \mathrm{m}$ glass microfiber filters (Millipore), preserved in brown glass containers with $0.5 \%$ methanol at $4{ }^{\circ} \mathrm{C}$, and later composited for an individual sample, followed by processing with $\mathrm{C} 18$ cartridge (Supelco Inc., USA) solid-phase extraction (SPE). Dissolved organic carbon (DOC) concentrations of filtered water samples were analyzed by using a total organic carbon (TOC) analyzer (model TOC-5000, Shimadzu, Japan) with a non-dispersive infrared detector and were approximately $57.7 \mathrm{mg} \mathrm{C} / \mathrm{L}$ at site A and $17.5 \mathrm{mg} \mathrm{C} / \mathrm{L}$ at site B. No biofouling was observed for TECAM of large size which was retrieved two days later. While moderate biofouling of small TECAM membranes was visually apparent by the end of the $16 \mathrm{~d}$ study at both sites, membrane surfaces at site A became more excessively colonized by Aufwuchs colonies with adhering fine-grained sediments.

\subsection{Sample processing and analysis}

Processing of field-deployed TECAM involved the complete removal of any exterior periphytic growth and then all TECAM were rinsed with distilled water and wiped up with clean tissue paper prior to extraction. Each TECAM was ultrasonically extracted three times with $20 \mathrm{~mL}$ of hexane as solvent for $10 \mathrm{~min}$ cycles and then dialyzed in $10 \mathrm{~mL}$ of hexane for $24 \mathrm{~h}$. Dialysis solutions of TECAM were combined and evaporated under a gentle stream of nitrogen. After extraction, solutions were combined and concentrated to $0.2 \mathrm{~mL}$ under a stream of $\mathrm{N}_{2}$. Each field water sample (2 L) was extracted and analyzed for contaminant content using C18 SPE cartridges (Supelco Inc., USA) solid-phase extraction technique.

The PAHs were analyzed using an Agilent 6890/5973 gas chromatography-mass spectrometer (GC-MS) equipped with a DB-5 MS silica-fused capillary column ( $30 \mathrm{~m} \times 0.25 \mathrm{~mm}$ inner diameter with $0.25 \mu \mathrm{m}$ film thickness). The temperature program for PAH analysis was as follows: initial temperature $40{ }^{\circ} \mathrm{C}$ for 1 min with a ramp of $6{ }^{\circ} \mathrm{C} / \mathrm{min}$ to $290^{\circ} \mathrm{C}$ and a final hold time of $3 \mathrm{~min}$; injector temperature $300^{\circ} \mathrm{C}$, detector temperature $280^{\circ} \mathrm{C}$. Selected ion monitoring (SIM) was used for analysis. Procedural blanks, field blanks and were routinely analyzed. Laboratory quality control procedures included analyses of method blanks (solvent), blank spikes, and matrix spikes. These samples were routinely analyzed with the field samples. Surrogate standard phenanthrene- $d_{10}$ was added to all the samples to monitor matrix effects. The recoveries of surrogate standard standards fell within a fairly narrow range $(88-112 \%)$. The recoveries of PAHs in blank spikes were 70.3-109.6\%, PAH concentrations were corrected using the recovery of the blank spikes.

All model calculations, simple linear regressions, and statistical tests were performed with the use of Origin for Windows version 8.0 (Microcal Software). The uptake and depletion were modeled using linear and nonlinear (Levenberg-Marquardt algorithm) regression analysis.

\subsection{Theory and modeling}

Passive sampling theory has been elucidated in many previous studies (Ke et al., 2007b), briefly, the exchange process between a passive sampler and water is described by a first-order, one-compartment model:

$C_{\mathrm{s}}=C_{\mathrm{w}} \frac{k_{\mathrm{u}}}{k_{\mathrm{e}}}\left(1-e^{-k_{\mathrm{e}} t}\right)$

Where $t$ is exposure time for the passive sampler, $C_{\mathrm{s}}$ is the concentrations of a target compound in the sampler at time $t$, and $C_{\mathrm{w}}$ is the concentration of analyte in water $k_{\mathrm{u}}$ is the uptake rate constant, $k_{\mathrm{e}}$ is the overall elimination rate constant.

In the initial uptake phase, analyte uptake is linear or integrative, for practical applications, Eq. (1) can be reduced to:

$C_{\mathrm{s}}=C_{\mathrm{w}} k_{\mathrm{u}} t$

Eq. (2) can be modified to correct for the presence of DOC and estimate the total dissolved concentration of a contaminant in water $\left(C_{t}\right)$ using. 
$C_{\mathrm{t}}=\left(1+C_{\mathrm{DOC}} K_{\mathrm{DOC}}\right) C_{\mathrm{TECAM}} / k_{\mathrm{u}} t$

Where $C_{\mathrm{DOC}}$ is the dimensionless mass ratio of DOC concentration in water and $K_{\mathrm{DOC}}$ is the partition coefficient of the chemical between water and the DOC. In this study it was assumed that $K_{\mathrm{DOC}}$ is equal to $0.11 K_{\mathrm{ow}}$ according to the relationship derived by Burkhard (Burkhard, 2000).

The uses of PRCs based on the evidence that the compound uptake and eliminate kinetics are governed by the same mass transfer law, and obey first-order isotropic exchange kinetics. Under conditions of isotropic exchange, the elimination rate constant $k_{\mathrm{e}}$ of a PRC from the passive sampler can be determined with the following first-order equation:

$k_{\mathrm{e}-\mathrm{PRC}}=\frac{\ln \left(C_{0} / C_{\mathrm{t}}\right)}{t}$

Where $t$ is exposure time for the passive sampler, $C_{0}$ and $C_{\mathrm{t}}$ are the concentration of PRCs in the sampler at time zero and $t$.

Huckins et al. (2002) introduced exposure adjustment factor (EAF) method to calculate the sampling rates in the field:

$\mathrm{EAF}=\frac{k_{\mathrm{u}, \text { field }}}{k_{\mathrm{u}, \mathrm{lab}}}=\frac{k_{\mathrm{e}-\mathrm{PRC}, \text { field }}}{k_{\mathrm{e}-\mathrm{PRC}, \mathrm{lab}}}$

Where $k_{\mathrm{u}, \text { field }}$ and $k_{\mathrm{u}, \mathrm{lab}}$ is the uptake rate of target analyte in the field and laboratory, respectively. The uptake rate of the analyte in the field is related to its uptake rate observed in the laboratory calibration by Eq. (5):

$k_{\mathrm{u}, \text { field }}=\mathrm{EAF}_{\mathrm{u}, \mathrm{lab}}=k_{\mathrm{u}, \mathrm{lab}} \frac{k_{\mathrm{e}-\mathrm{PRC}, \text { field }}}{k_{\mathrm{e}-\mathrm{PRC}, \mathrm{lab}}}$

However, one of the difficulties with this EAF method is that calibration data for target compounds $\left(k_{\mathrm{u}, \mathrm{lab}}\right)$ and PRCs $\left(k_{\mathrm{e}-\mathrm{PRC}}\right)$ measured under controlled laboratory conditions is not always available and has to be estimated from compounds with similar properties. To avoid these difficulties, a revised PRC-based methodology that yields sampling rate estimates based on all available calibration data (empirical uptake model). The sampling rates $\left(R_{\mathrm{s}, \mathrm{i}}\right)$ of analytes can be estimated from Eq. (7):

$R_{\mathrm{s}, \mathrm{i}}=R_{\mathrm{s}, \mathrm{PRC}} \frac{\alpha_{\mathrm{i}}}{\alpha_{\mathrm{PRC}}}$

Where $\alpha_{\mathrm{i}}$ is unitless compound-specific effect, using the results of nine laboratory calibration studies, Huckins et al. (2006) modeled the compound-specific effect on the sampling rates of SPMD as follows:

$\log \alpha_{i}=0.0130 \log K_{\mathrm{OW}}^{3}-0.3173 \log K_{\mathrm{OW}}^{2}+2.244 \log K_{\mathrm{OW}}$

Thus when PRC-derived sampling rates are available, Eq. (7) can be used to calculate sampling rates of other analytes. This formula is not very suitable for higher $\log K_{\mathrm{ow}}$ compounds, Eq. (8) indicates that the compound-specific effects on $R_{\mathrm{S}}$ decrease by a factor of 6 over the range $5.2<\log K_{\mathrm{ow}}<8.5$, which is much larger than expected from theory (Huckins et al., 2002, 2006; Ellis et al., 2008).

Assuming that mass transfer is controlled by the transport resistance of water boundary layer (WBL), Huckins et al. (2006) postulated that the sampling rate of analytes is related to the sampling rate of PRCs as follows (WBL uptake model):

$R_{\mathrm{S}}=R_{\mathrm{S}, \mathrm{PRC}}\left(\frac{V_{\mathrm{PRC}}}{V}\right)^{0.39}$

Where $V$ is the LeBas molar volume. This equation predicts a 1.4 fold reduction of sampling rates over the commonly encountered molar volume range $199-480 \mathrm{~cm}^{3}$ / mol.

\section{Results and discussion}

\subsection{Effects of temperature}

The relationship between uptake rate constants $k_{\mathrm{u}}$ of the test analytes and temperature can be compared at four temperatures $\left(5,15,25\right.$ and $\left.35^{\circ} \mathrm{C}\right)$. In general, the $k_{\mathrm{u}}$ increases with the increasing exposure temperature, which showed an average factor of 3.8 increasing over the temperature from 5 to $35^{\circ} \mathrm{C}$ (Fig. 1). Similar effects have also been found in SPMDs, sampling rates at $30^{\circ} \mathrm{C}$ were higher than $2{ }^{\circ} \mathrm{C}$ at a factor of about 3 (Booij et al., 2003), a increasing sampling rate by a factor of 5.2 over the temperature range from 6 to $18{ }^{\circ} \mathrm{C}$ was also found in the Chemcatcher (Vrana et al., 2006b). The results indicate that, even for a temperature difference of $30^{\circ} \mathrm{C}$, changes in chemical uptake rates by TECAM are limited to a factor of about 4 . This means that difference in absorbed amounts generally cannot be

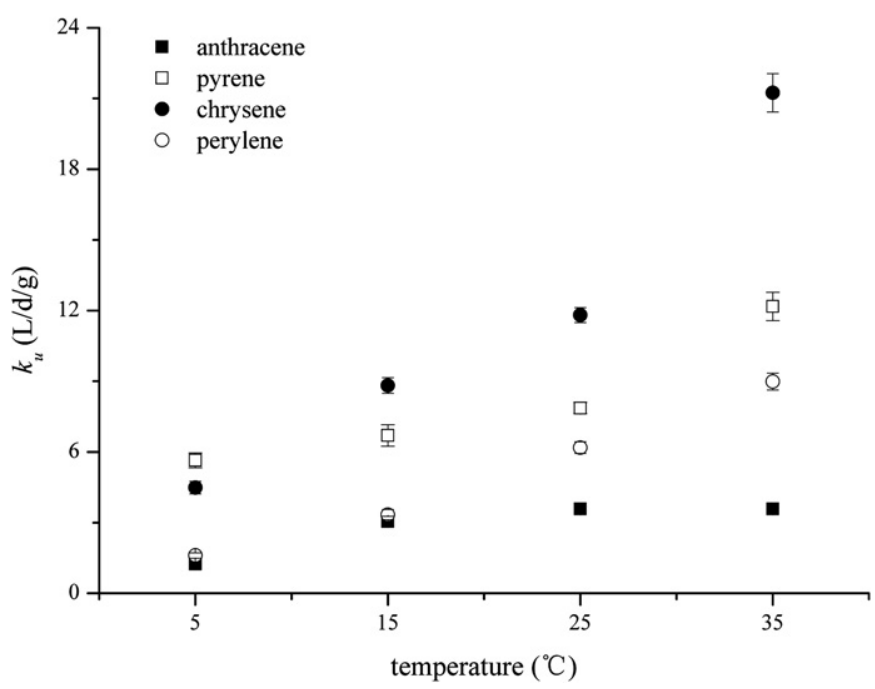

Fig. 1. Effect of temperature on selective PAHs uptake rate constants. Data are presented from semi-static experiment.

attributed to temperature difference, except large geographical and temporal scales are involved. And for field application of passive samplers, researchers suggested that temperature is not a key factor determining uptake rates (Huckins et al., 1999; Booij et al., 2003).

Typically, increasing temperature can enhance mass transfer in all media. The effects of temperature on the uptake rates can be quantified in terms of activation energies $\left(\Delta E_{\mathrm{a}}\right)$ for mass transfer. The temperature dependence of the uptake rate $k_{\mathrm{u}}$ can be described by the equation:

$\ln R_{\mathrm{s}}=\ln A-\frac{\Delta E_{\mathrm{a}}}{R T}$

Where $R$ is the universal gas constant $\left(\mathrm{kJ} \mathrm{mol}^{-1} \mathrm{~K}^{-1}\right), A$ is the preexponential factor expressing the maximum uptake rate at infinite temperature, $T$ is the absolute temperature (K). Values of $\Delta E_{\mathrm{a}}$ were obtained by plotting the natural logarithm of $R_{\mathrm{S}}$ against the reciprocal value of absolute temperature $(1 / T)$, because $R_{\mathrm{S}}$ values are proportional to the volume of passive samplers, here we use $k_{\mathrm{u}}$ to replace $R_{\mathrm{s}}$, so the volume factor of passive samplers is excluded. The activation energy can then be calculated by multiplying the slope of the regression line with the gas constant. The calculation of the activation $\Delta E_{\mathrm{a}}$ using Eq. (10) was performed on the semi-static experiment. The activation energies for anthracene, pyrene, chrysene and perylene were $24.1,17.4,35.3$, and $41.3 \mathrm{~kJ} \mathrm{~mol}^{-1}$, respectively. The values were very close to SPMD (Huckins et al., 2006) and much less than Chemcatcher (Vrana et al., 2006b). Thus the effects of temperature on TECAM uptake kinetics are similar to that on SPMD and less sensitive than that on Chemcatcher. Therefore, it suggests that water temperatures have only small effects on TECAM uptake rate constants in the field, unless large temperature differences exist between exposure sites or exposure periods.

\subsection{Effects of water flow rates}

The effect of the water boundary layer resistance to mass transfer can be investigated when studies are conducted under various hydrodynamic conditions. The exposures were conducted at various flow rates use flow-through system. Concentrations of the analytes in water $\left(C_{\mathrm{w}}\right)$ and in TECAM samplers $\left(C_{\mathrm{s}}\right)$ were two parameters measured regularly during the continuous flow exposures. During the whole exposure period, the nominal water 
concentration was held constant, which was confirmed by actual analysis. Uptake curves were fitted using nonlinear regression analysis (Eq. (1)). A significant increase of uptake rates with increasing flow velocity was observed for all compounds under investigation $(p<0.05)$ (Fig. 2). A 1.5 -fold fold increase in $k_{\mathrm{u}}$ values was found with the increase in flow rates from 0.1 to $0.4 \mathrm{~cm} / \mathrm{s}$ (Fig. 2). Similar effects were also found on the release of PRCs from TECAM, a 4-fold increase in flow rates from 0.1 to $0.4 \mathrm{~cm} / \mathrm{s}$ results in a 1.6-fold increase in $k_{\mathrm{e}}$ values (pyrene-d10). It means that the accumulation kinetics of hydrophobic compounds ( $\left.\log K_{\text {ow }}>4\right)$ are governed by the water boundary layer in flow velocity ranged from 0.1 to $0.4 \mathrm{~cm} / \mathrm{s}$ and sensitive to slight changes in flow rates. This corresponds well with the passive sampling theory of hydrophobic organic compounds (Huckins et al., 2006). Similar effects have been observed and explained well for other passive samplers such as SPMD (Vrana and Schuurmann, 2002), Chemcatcher (Vrana et al., 2006a) and membrane-enclosed sorptive coating (MESCO) (Vrana et al., 2006b).

Under conditions of low water flow rates, compounds with $\log K_{\mathrm{ow}}>4.5$ are generally under WBL control (Huckins et al., 2006), the flow velocity is a key factor to accurately estimate ambient chemical concentrations, as their $k_{\mathrm{u}} \mathrm{s}$ are quite sensitive to site hydrodynamics. For example, it was reported that the average exchange rates of chemicals between SPMD and water decreased by a factor of 4 under conditions of low turbulence (Booij et al., 1998), some researchers also suggested that it is absolutely necessary to manage the effects of flow regime on the SPMD exchange kinetics (a 5-fold increase in flow rate from 0.06 to $0.28 \mathrm{~cm} \mathrm{~s}^{-1}$ resulting in a 3-fold increase in $k_{\mathrm{e}}$ was found for antd10) (Vrana and Schuurmann, 2002).

\subsection{Verification of isotropic exchange kinetics: adsorption versus desorption}

The use of several pairs of deuterated and non-deuterated PAHs allowed direct comparison of the uptake and release processes. Curves describing the uptake of anthracene and the release of anthracene-d 10 intersect at about $50 \%$ of the concentration interval (Fig. 3), which demonstrates the isotropy of the adsorption and desorption process. It also implies that by knowing the behavior of the desorption standard, the adsorption of the analytes can be understood. Similar profiles were also observed for other uptake compounds and their deuterated analogs. Therefore, the release of

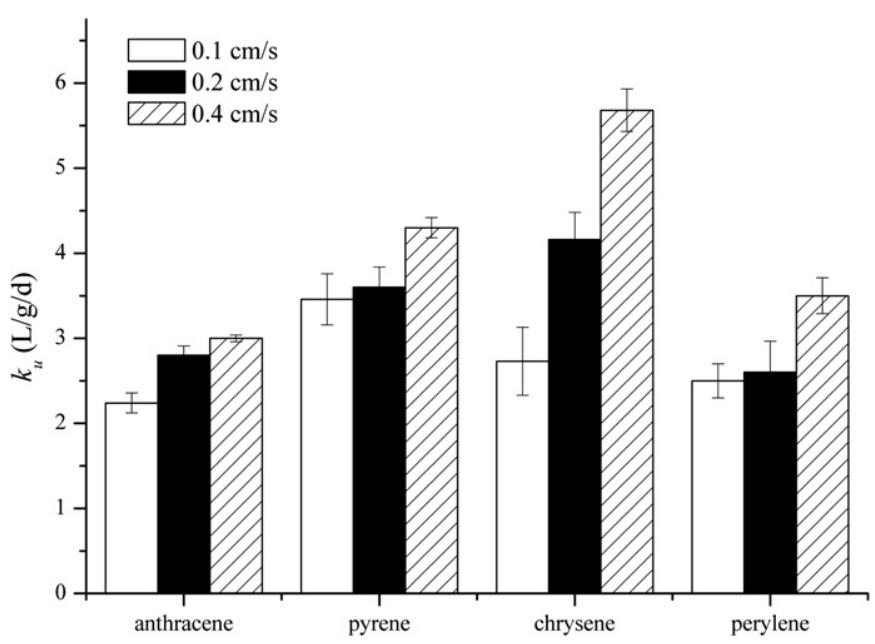

Fig. 2. Effect of flow velocity on PAHs uptake rate constants. Data are presented from the flow-though exposure conducted at $22^{\circ} \mathrm{C}$.

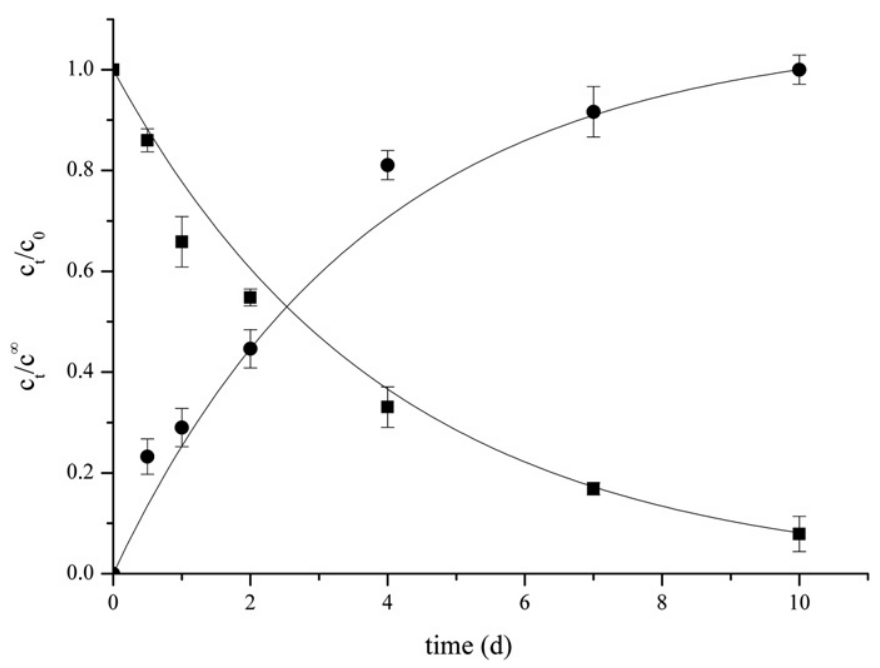

Fig. 3. The uptake of anthracene ( $)$ and release of anthracene-d10 ( $\boldsymbol{\square})$ by TECAM at the flow rate of $0.1 \mathrm{~cm} / \mathrm{s}$.

PRCs can be used for in situ calibration of the uptake process in TECAM.

\subsection{PRCs release kinetics}

The PRCs method suffers from the difficulty that some PRCbased $k_{\mathrm{u}}$ estimate must be rejected due to the fact that the retained amounts are either too close to the detection limit or too close to the initial amounts (Booij and Smedes, 2010; Rusina et al., 2010). To exclude the contribution of inaccurate $k_{\mathrm{u}}$ estimates, some researchers recommended that the amount of retained PRCs should be larger than $20 \%$ of the initial amount and smaller than 80\% (Soderstrom and Bergqvist, 2004; Gouin et al., 2005). After 10 days of exposure in flow-through system, 96\% losses for anthracene-d $10,75 \%$ and $58 \%$ losses for pyrene-d 10 and chrysene$\mathrm{d} 12$, respectively (Fig. 4). The losses of pyrene-d10 and chrysened12 are range of $20-80 \%$ of the initial amount. For this reason, pyrene-d10 is the most suitable PRC for use in TECAM which has the middle hydrophobicity $\left(\log K_{\mathrm{ow}}=4.88\right)$. For a correction of the uptake rates in situ with pyrene-d10, we assume that the kinetics of other PAHs uptake and the kinetics of pyrene-d10 are closely related.

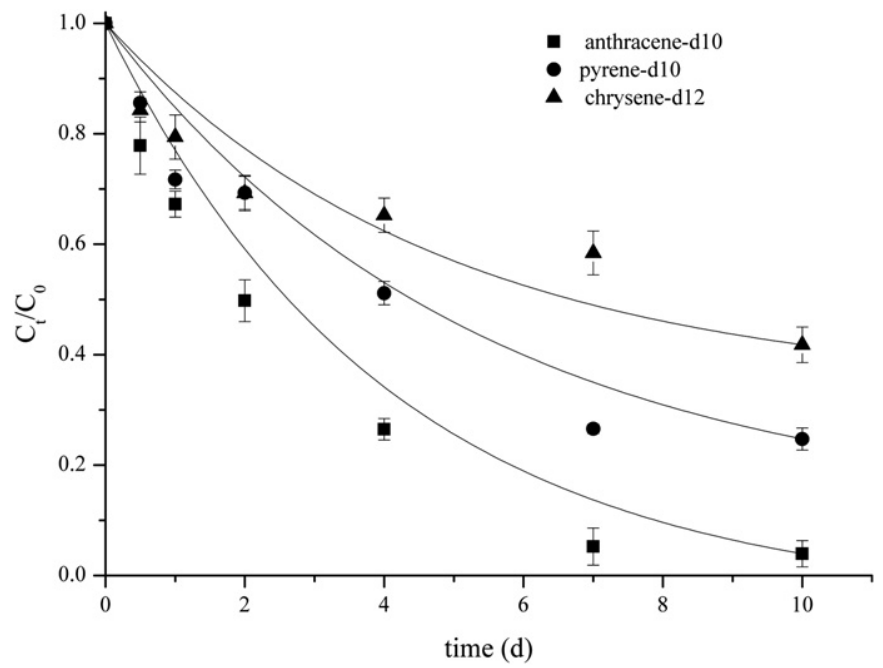

Fig. 4. Typical release curves of PRCs from TECAM. Data are presented from the flowthrough exposure conducted at $22^{\circ} \mathrm{C}$ with the flow rate of $0.4 \mathrm{~cm} / \mathrm{s}$. 


\subsection{Laboratory verification}

By dividing $k_{\mathrm{u}}$ values by $k_{\mathrm{u}-\mathrm{PRC}}$, the bias or error encompassing the difference between predicted and measured of $k_{\mathrm{u}}$ can be estimated. There are three methods for application of PRCs to estimate $k_{\mathrm{u}}$ : EAF method, empirical and WBL model. Application of three approaches to our laboratory uptake rates data gave the following the mean $k_{\mathrm{u}} / k_{\mathrm{u}-\mathrm{PRC}}, 0.88 \pm 0.16,1.64 \pm 0.34$ and $1.58 \pm 0.45$, for EAF method, empirical and WBL model, respectively. This is good agreement between uptake rates values calculated from uptake and release kinetics. Vrana et al. (2006b) and Huckins et al. (2002) have also demonstrated a 2-fold difference in comparison of measured and PRCs-predicted sapling rates for membrane-enclosed sorptive coating MESCO and SPMD. The empirical and WBL model were applied for field performance.

\subsection{Field application}

The PRC-corrected $k_{\mathrm{u}}$ values for the 14 PAHs were obtained using the empirical uptake model, the $k_{\mathrm{u}}$ values were highest for fluoranthene, pyrene, chrysene ( $\left.\log K_{\mathrm{ow}} 4.9-5.16\right)$ and varied from 0.99 to $5.85 \mathrm{~L} \mathrm{~g}^{-1} \mathrm{~d}^{-1}$ at the two different sampling sites. The exposure conditions at the two sampling sites clearly differed, because there were significant between-site variations in PRCs losses ( $32 \%$ loss at site A and 69\% loss at site B after 1 day exposure for pyrene-d10).

The $C_{\mathrm{TWA}} \mathrm{S}$ of PAHs at two different sampling sites were estimated from the analytes quantified in TECAM after field exposure using the PRCs-corrected $k_{\mathrm{u}}$ values. Eq. (3) was used to calculate the $C_{\text {TWA }}$. The measured dissolved concentrations of PAHs were based on DOC corrected field measurements of the water samples using SPE. Corrections were not made for POC because the water samples were filtered prior to analysis. Concentrations of PAHs dissolved in water were estimated from the calibrated sampling rates and PAHs residues in the unfortified field-deployed TECAMs. The measured concentrations were compared to predict dissolved PAHs concentrations in Fig. 5. In both cases, most PAHs concentrations are underestimated and the greatest difference from unity occurs with the higher molecular weight. The average measured: predicted ratio is $0.87 \pm 0.63$ (empirical model) and $0.67 \pm 0.49$ (WBL model) at site $\mathrm{A}$, and $0.70 \pm 0.72$ (empirical model) and $0.54 \pm 0.55$ (WBL model) at site B for DOC corrected measurements, respectively. The results indicated that use of PRCs concept approach to estimate accuracy dissolved PAHs in TECAM is validated, and empirical model shows more accuracy than WBL model.

In general, our results are consistent with the result of PRCs fortified SPMDs in a previous study (Luellen and Shea, 2002). Most of the DOC corrected predicted PAHs values are within a factor of 2 in either direction of measured dissolved PAHs on the whole.

Additionally, one must recognize the uncertainty inherent in these calculations for both sites. The bias of using SPE to estimate an actual TWA concentration if the concentration in water fluctuates, can be expected. Considering the integrative nature of TECAM, more discrete water samples would improve the prediction despite the cost.

The use of PRCs only allow determination of sampling rates over a small range of hydrophobicity, knowledge of the relationship between $R_{\mathrm{S}}$ and $K_{\mathrm{ow}}$ is required in order to apply $R_{\mathrm{S}}$ estimated from dissipation of PRCs to compounds in a higher $K_{\mathrm{ow}}$ range (Rusina et al., 2010). Huckins et al. (2006) showed that for SPMD differences in exposure conditions cause sampling rates to be shifted by a constant factor for all compounds, the profile could be described by a third order polynomial function of $\log K_{\text {ow }}$. Vrana et al. (2007) recently published a similar empirical model for the Chemcatcher samplers using a polynomial that described the relation of $R_{S}$ with $K_{\mathrm{ow}}$, with much stronger decline of higher of $R_{\mathrm{S}}$ in the higher $K_{\mathrm{ow}}$ range. In this paper, when use PRCs to estimate in situ $k_{\mathrm{u}}$ in TECAM, the SPMD empirical model was applied. For future use of PRCs to accurately estimate in situ $k_{\mathrm{u}}$ in TECAM, more calibration data are needed to elucidate the relation between $k_{\mathrm{u}}$ with $K_{\mathrm{ow}}$ for TECAM.

In this paper, we did not consider the effects of biofouling on $k_{\mathrm{u}}$ values, because evidence has accumulated which suggests that exchange rates would not be significantly affected by the biofouling when differences in uptake rates are quantitatively reflected by the dissipation rates of PRCs (Booij et al., 2006; Polidoro et al., 2009).
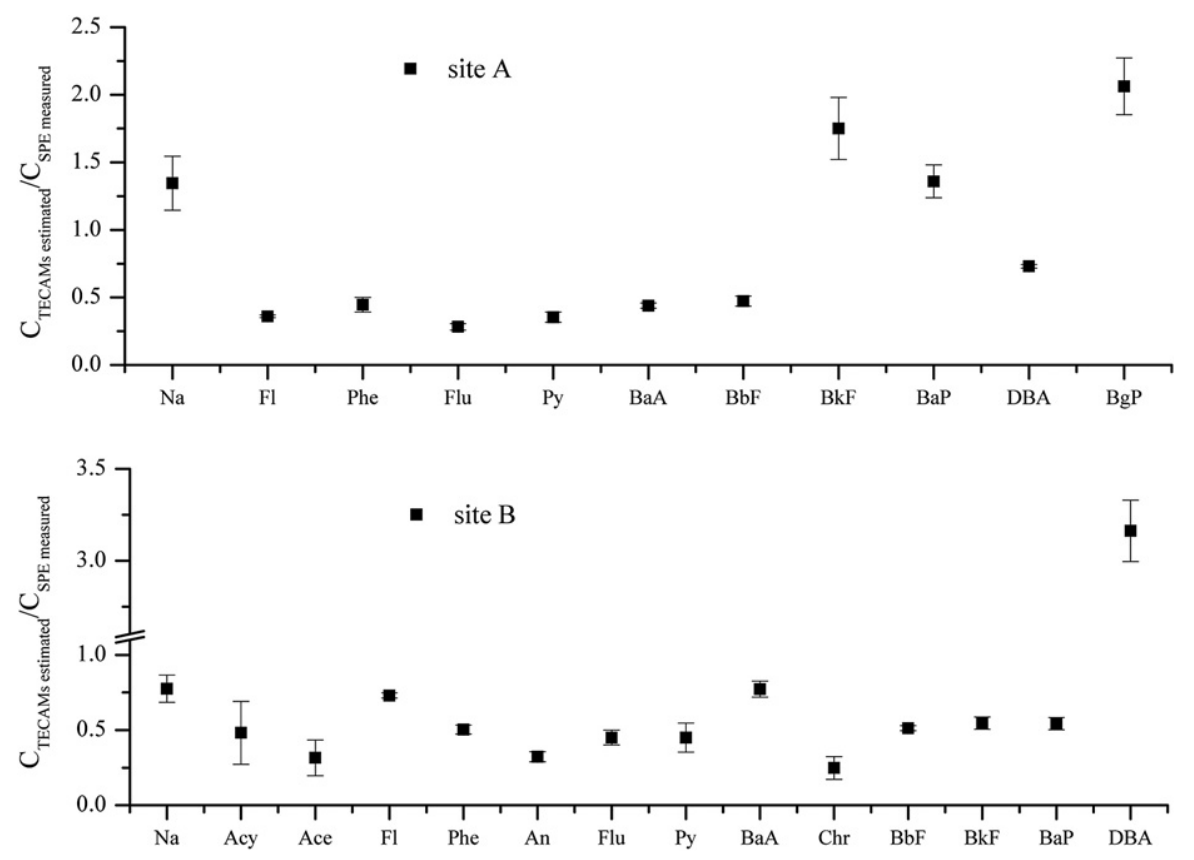

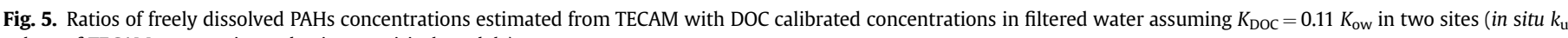
values of TECAM were estimated using empirical models). 


\section{Conclusion}

This paper provided a calibration data necessary for reliable integrative sampling of hydrophobic micro-pollutants in aquatic environment. It characterized the effect of two main environmental variables, temperature and water flow velocity, on TECAM performance. The implication of the experiment demonstrating the isotropic exchange process, is that by knowing the behavior of either adsorption or desorption process, the opposite one can also be understood. This finding can be used practically for in situ calibration of TECAM using PRCs.

This study contributes to the growing pool of evidence indicating that the PRCs concept is widely applicable for the determination of in situ sampling kinetics, required for more accurate measurement of $C_{\text {TWA }}$ using integrative passive samplers. The successful application of the PRCs approach with other passive samplers including the SPMD (Huckins et al., 2002), Chemcatcher (Vrana et al., 2006a), MESCO (Vrana et al., 2006b), silicone rubber passive samplers (Rusina et al., 2010) and POCIS (Mazzella et al., 2010). This concept has also been applied to passive air samplers, such as SPMDs (Soderstrom and Bergqvist, 2004) and polyurethane foam samplers PUF (Kennedy et al., 2010).

Our future work will focus on demonstrating the practical application of the laboratory calibration data and use PRCs for the measurement of $C_{\mathrm{TWA}}$ of priority pollutants in field. In addition, more research is necessary to provide on understanding the effects of biofouling and fluctuation of water concentration on TECAM passive sampler.

\section{Acknowledgment}

This work was funded by the National Natural Science Foundation of China (40801204), National Science and Technology Major Project of China (2009ZX07527-005), and State Key Laboratory of Environmental Aquatic Chemistry of China (10Y03ESPCR).

\section{Appendix. Supplementary data}

Supplementary material associated with this article can be found, in the online version, at doi:10.1016/j.envpol.2012.01.013.

\section{References}

Adams, R.G., Lohmann, R., Fernandez, L.A., Macfarlane, J.K., Gschwend, P.M., 2007. Polyethylene devices: passive samplers for measuring dissolved hydrophobic organic compounds in aquatic environments. Environmental Science \& Technology 41, 1317-1323.

Booij, K., Hofmans, H.E., Fischer, C.V., Van Weerlee, E.M., 2003. Temperaturedependent uptake rates of nonpolar organic compounds by semipermeable membrane devices and low-density polyethylene membranes. Environmental Science \& Technology 37, 361-366.

Booij, K., Sleiderink, H.M., Smedes, F., 1998. Calibrating the uptake kinetics of semipermeable membrane devices using exposure standards. Environmental Toxicology and Chemistry 17, 1236-1245.

Booij, K., Smedes, F., 2010. An improved method for estimating in situ sampling rates of nonpolar passive samplers. Environmental Science \& Technology 44, 6789-6794.

Booij, K., van Bommel, R., Mets, A., Dekker, R., 2006. Little effect of excessive biofouling on the uptake of organic contaminants by semipermeable membrane devices. Chemosphere 65, 2485-2492.

Burkhard, L.P., 2000. Estimating dissolved organic carbon partition coefficients for nonionic organic chemicals. Environmental Science \& Technology 34 4663-4668.

Ellis, S.G., Booij, K., Kaputa, M., 2008. Comparison of semipermeable membrane device (SPMD) and large-volume solid-phase extraction techniques to measure water concentrations of $4,4^{\prime}$-DDT, 4,4'-DDE, and 4,4'-DDD in Lake Chelan, Washington. Chemosphere 72, 1112-1117.

Esteve-Turrillas, F.A., Pastor, A., Yusa, V., de la Guardia, M., 2008. New perspectives in the use of semipermeable membrane devices as passive samplers. Talanta 74, 443-457.

Esteve-Turrillas, F.A., Yusa, V., Pastor, A., de la Guardia, M., 2007. Using semipermeable membrane devices as passive samplers. Trac-Trends in Analytical Chemistry 26, 703-712.
Fernandez, L.A., Harvey, C.F., Gschwend, P.M., 2009. Using performance reference compounds in polyethylene passive samplers to deduce sediment porewater concentrations for numerous target chemicals. Environmental Science \& Technology 43, 8888-8894.

Gorecki, T., Seethapathy, S., Li, X.J., 2008. Passive sampling in environmental analysis. Journal of Chromatography A 1184, 234-253.

Gouin, T., Harner, T., Blanchard, P., Mackay, D., 2005. Passive and active air samplers as complementary methods for investigating persistent organic pollutants in the Great Lakes basin. Environmental Science \& Technology 39, 9115-9122.

Greenwood, R., Mills, G.A., Vrana, B., 2009. Potential applications of passive sampling for monitoring non-polar industrial pollutants in the aqueous environment in support of REACH. Journal of Chromatography A 1216, 631-639.

Huckins, J.N., Petty, J.D., Lebo, J.A., Almeida, F.V., Booij, K., Alvarez, D.A., Clark, R.C., Mogensen, B.B., 2002. Development of the permeability/performance reference compound approach for in situ calibration of semipermeable membrane devices. Environmental Science \& Technology 36, 85-91.

Huckins, J.N., Petty, J.D., Orazio, C.E., Lebo, J.A., Clark, R.C., Gibson, V.L., Gala, W.R., Echols, K.R., 1999. Determination of uptake kinetics (sampling rates) by lipidcontaining semipermeable membrane devices (SPMDs) for polycyclic aromatic hydrocarbons (PAHs) in water. Environmental Science \& Technology 33, 3918-3923.

Huckins, J.N., Petty, J.D., Booij, K., 2006. Monitors of Organic Contaminants in the Environment: Semipermeable Membrane Devices. Springer Verlag, New York.

Ke, R.H., Wang, Z.J., Huang, S.B., Khan, S.U., 2007a. Accurate quantification of freely dissolved organochlorine pesticides in water in the presence of dissolved organic matter using triolein-embedded cellulose acetate membrane. Analytical and Bioanalytical Chemistry 387, 2871-2879.

Ke, R.H., Xu, Y.P., Huang, S.B., Wang, Z.J., Huckins, J.N., 2007b. Comparison of the uptake of polycyclic aromatic hydrocarbons and organochlorine pesticides by semipermeable membrane devices and caged fish (Carassius carassius) in Taihu Lake, China. Environmental Toxicology and Chemistry 26, 1258-1264.

Kennedy, K., Hawker, D.W., Bartkow, M.E., Carter, S., Ishikawa, Y., Mueller, J.F., 2010. The potential effect of differential ambient and deployment chamber temperatures on PRC derived sampling rates with polyurethane foam (PUF) passive air samplers. Environmental Pollution 158, 142-147.

Luellen, D.R., Shea, D., 2002. Calibration and field verification of semipermeable membrane devices for measuring polycyclic aromatic hydrocarbons in water. Environmental Science \& Technology 36, 1791-1797.

Mazzella, N., Lissalde, S., Moreira, S., Delmas, F., Mazellier, P., Huckins, J.N., 2010. Evaluation of the use of performance reference compounds in an oasis-HLB adsorbent based passive sampler for improving water concentration estimates of polar herbicides in freshwater. Environmental Science \& Technology 44, 1713-1719.

O’Brien, D.O.B.D.S., Booij, K., Hawker, D.W., Mueller, J.F., 2011. Method for the in situ calibration of a passive phosphate sampler in estuarine and marine waters. Environmental Science \& Technology 45, 2871-2877.

Polidoro, B.A., Morra, M.J., Ruepert, C., Castillo, L.E., 2009. Pesticide sequestration in passive samplers (SPMDs): considerations for deployment time, biofouling, and stream flow in a tropical watershed. Journal of Environmental Monitoring 11, 1866-1874.

Richardson, B.J., Lam, P.K.S., Zheng, G.J., McClellan, K.E., De Luca-Abbott, S.B., 2002. Biofouling confounds the uptake of trace organic contaminants by semipermeable membrane devices (SPMDs). Marine Pollution Bulletin 44, 1372-1379.

Rubio, S., Ballesteros-Gomez, A., 2011. Recent advances in environmental analysis. Analytical Chemistry 83, 4579-4613.

Rusina, T.P., Smedes, F., Koblizkova, M., Klanova, J., 2010. Calibration of silicone rubber passive samplers: experimental and modeled relations between sampling rate and compound properties. Environmental Science \& Technology 44, 362-367.

Soderstrom, H., Lindberg, R.H., Fick, J., 2009. Strategies for monitoring the emerging polar organic contaminants in water with emphasis on integrative passive sampling. Journal of Chromatography A 1216, 623-630.

Soderstrom, H.S., Bergqvist, P.A., 2004. Passive air sampling using semipermeable membrane devices at different wind-speeds in situ calibrated by performance reference compounds. Environmental Science \& Technology 38, 4828-4834.

Tao, Y.Q., Zhang, S.Z., Wang, Z.J., Christie, P., 2009. Predicting bioavailability of PAHs in field-contaminated soils by passive sampling with triolein embedded cellulose acetate membranes. Environmental Pollution 157, 545-551.

Vrana, B., Mills, G.A., Dominiak, E., Greenwood, R., 2006a. Calibration of the chemcatcher passive sampler for the monitoring of priority organic pollutants in water. Environmental Pollution 142, 333-343.

Vrana, B., Mills, G.A., Kotterman, M., Leonards, P., Booij, K., Greenwood, R., 2007. Modelling and field application of the chemcatcher passive sampler calibration data for the monitoring of hydrophobic organic pollutants in water. Environmental Pollution 145, 895-904.

Vrana, B., Paschke, A., Popp, P., 2006b. Calibration and field performance of membrane-enclosed sorptive coating for integrative passive sampling of persistent organic pollutants in water. Environmental Pollution 144, 296-307.

Vrana, B., Schuurmann, G., 2002. Calibrating the uptake kinetics of semipermeable membrane devices in water: impact of hydrodynamics. Environmental Science \& Technology 36, 290-296.

Xu, Y.P., Wang, Z.J., Ke, R.H., Khan, S.U., 2005. Accumulation of organochlorine pesticides from water using triolein embedded cellulose acetate membranes. Environmental Science \& Technology 39, 1152-1157. 